\title{
LESSONS FROM EMPIRICAL STUDIES IN SUPPLY CHAIN FLEXIBILITY: A MATURITY PERSPECTIVE
}

Raquel Mello

raquel.mello@uni-muenster.de

University of Münster

\section{Bernd Hellingrath}

bernd.hellingrath@wi.uni-

muenster.de

University of Münster

\section{Roberto Antonio Martins}

ram@dep.ufscar.br

Federal University of São Carlos, São Carlos, São Paulo, Brazil.

\section{ABSTRACT}

Goal: To analyze supply chain flexibility (SCF) within real-life settings from a maturity perspective and provide a discussion on the importance of a maturity model for SCF.

Design/Methodology/Approach: A multiple case study was conducted in multinational manufacturing companies from different business sectors, offering a within-case and cross-case analysis.

Results: The empirical evidence revealed that the studied companies do not consider flexibility measures. This absence renders difficulties when striving for external flexibility, for instance, affecting planning and control activities. Furthermore, the conducted analysis showed that sharing information among supply chain members has a significant impact on the identification of changes in the processes, enabling a correct and quick reaction to these changes.

Limitations of the investigation: The results are restricted to the studied companies; therefore, the SCF maturity model deserves more application through the development of more empirical investigations.

Practical implications: This is a guide for practitioners to identify the current maturity level of their SCF, and subsequently improve the processes, aiming to achieve the desired result.

Originality/Value: This paper addresses the lack of theoretical and empirical studies in the literature regarding the analysis of SCF maturity and its different levels, thus enabling practitioners and researchers to improve the understanding of maturity in the SCF context.

Keywords: Supply Chain Flexibility; Maturity Model; Flexibility Dimensions; Case Study. 


\section{INTRODUCTION}

Supply chain flexibility (SCF) is a relevant issue in today's business environment to manage uncertainties and variations in supply, demand, production, and logistics, aiming to provide maximum value to customers (Esmaeilikia et al., 2016; Manders et al., 2016; Huo et al., 2018). This paper follows Hellingrath and Pfeiffer (2011, p. 25) and defines SCF as "the ability of a supply chain to change its structures, processes, resources, and steering mechanisms in the bounds of a given scope of action".

Supply chain flexibility can occur internally and externally within an organization (Manders et al., 2017). Internal flexibility concerns different areas, which should work synergistically to respond to variations or uncertainties occurring inside the company. External flexibility regards processes and activities involving the company's external customers and suppliers (Huo et al., 2018). Companies developing only internal flexibility while their suppliers are rigid can face a constrained supply chain (SC) (Sushil, 2012). Therefore, SCF should consider both internal and external flexibility dimensions (Sánchez and Pérez, 2005). Flexible SC rapidly adjusts capacities to attend unpredicted demand, and launch new products fast (Vickery et al., 1999; Thomé et al., 2014b).

Maturity models give companies guidance to examine and subsequently improve their processes (Fischer et al., 2016). As each SC aims to reach a different level of flexibility, identifying the maturity level of the SCF allows determining where flexibility is needed and the extent to which it is required. Maturity models support the identification of current maturity stage (as-is diagnosis) and a desirable future stage, guiding the creation and improvement of SCF to make organizations more competitive (Sushil, 2012).

There is a lack in the literature of theoretical and empirical studies regarding the analysis of SCF maturity and its different levels. Therefore, there is a need to improve the understanding of maturity in the SCF context. This paper has the objective of addressing the lack of these studies by analyzing SCF within real-life settings from a maturity perspective. Additionally, this paper provides a discussion on maturity model for SCF as well as conducts a multiple case study to reveal empirical insights of its use in the industry and establish the relations among the flexibility dimensions of this maturity model. The multiple case study was conducted in multinational manufacturing companies from different business sectors, offering a within-case and cross-case analysis.

This paper is organized as follows. First, the theoretical background of SCF and maturity models is provided. Next, the adopted research method is presented. Then, empirical findings from the multiple case study are analyzed and discussed. Finally, the paper offers a conclusion and suggestions for future work.

\section{THEORETICAL BACKGROUND}

This section introduces the topics of SCF and maturity models for SC management (SCM). Also, an SCF maturity model is depicted including its different dimensions and levels.

\section{Supply chain flexibility}

Flexibility is the ability to change or to react in the face of uncertainty, i.e. the handling of the variability (Upton, 1994). The central focus of flexibility lies in what can be changed (Slack, 1987). Upton (1994) distinguished external flexibility from internal flexibility. Internal flexibility refers to the company's capabilities, such as machine, labor, and handling flexibility (Upton, 1995). Customer experiences are related to external flexibility, which is associated with the ability of the company to change its product mix, production volume, and delivery (Thomé et al., 2014b).

The research on flexibility in operations management stems from a debate about manufacturing flexibility (Sethi and Sethi, 1990; Gerwin, 1993), which refers to the capability to fulfill different requests from many customers, controlling production resources and managing uncertainty, while maintaining high performance (Zhang et al., 2003).

The flexibility concept has been extended beyond the borders of a single company into the SC by "looking at those components that make an organization flexible and extends them beyond the organization's boundaries to other nodes in the supply chain" (Lummus et al., 2003). The research on SCF gained importance in the last decade, and more empirical research on the topic has been conducted (Thomé et al., 2014b; Manders et al., 2017; Dwaikat et al., 2018).

Flexibility plays an essential role in SC, creating an advantage over competitors by enabling the ability to cope with uncertainty and changes in customer requirements. Flexibility at all levels of manufacturing and in the SC has become a strategic core competency for companies dealing with a volatile business environment (Yu et al., 2015). All SC members should be flexible in response to variations, aim to fulfill the final customer demand, and attend customers' requests (Lummus et al., 2003; Thomé et al., 2014b).

Flexibility in the SC differs due to characteristics such as the level of awareness for the need for flexibility, and the use of flexibility (Fischer et al., 2016). Maturity models permit managers to analyze, create, and improve the company's flexibility to become more competitive and to better 
manage the uncertainties of the business environment (Sushil, 2012). The next section presents the concept of maturity models for SCM.

\section{Maturity models for supply chain management}

The concept of maturity model has been increasingly used and held in high regard across SCM. Maturity models are valuable tools to assist decision-making and guide companies to achieve their desired result. Through the application of such a model, managers are capable of visualizing their results and the next steps towards a higher level (Garcia Reyes and Giachetti, 2010).

The general starting point on research about maturity models was made with the Capability Maturity Model developed by the Software Engineering Institute of the University Carnegie Mellon (Paulk et al., 1993). Bowersox et al. (2000) focused on the integration and collaboration of SC, proposing a simple scale to evaluate the level of adoption or realization of modern collaboration and integration practices in SCM. Ayers and Malmberg (2002) introduced a four-level model for implementing information technology to support SCM. The emphasis of this model is on the enabling elements for implementing information technology.

Lockamy III and McCormack (2004) proposed an SCM process maturity model with five levels for enhanced SC performance. Wadhwa and Rao (2002) suggested a maturity model for manufacturing flexibility, which can be used by companies that want to increase their flexibility maturity.

Although several SC maturity models can be found in literature, only one deals with levels of maturity in terms of SCF, and it was introduced by Fischer et al. (2016). This finding reinforces that research on SCF maturity is still incipient. The next section presents the model proposed by Fischer et al. (2016).

\section{Supply chain flexibility maturity model}

The maturity model from Fischer et al. (2016) includes five maturity levels. Starting from Level 1 (No Flexibility), where flexibility is of no concern, until Level 5 (Paradigmatic

Figure 1. SCF Maturity Model

\begin{tabular}{|c|c|c|c|c|c|c|}
\hline & & Level 1 & Level 2 & Level 3 & Level 4 & Level 5 \\
\hline & 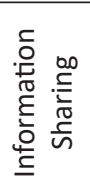 & $\begin{array}{l}\text { No information } \\
\text { sharing on flex- } \\
\text { ibility }\end{array}$ & $\begin{array}{l}\text { Internal data } \\
\text { shared among } \\
\text { functional units }\end{array}$ & $\begin{array}{c}\text { Moderate integration of exter- } \\
\text { nal and internal SC data }\end{array}$ & $\begin{array}{l}\text { Planning information } \\
\text { exchanged among key } \\
\text { SC partners (e.g. suppli- } \\
\text { er capacity availability) }\end{array}$ & $\begin{array}{c}\text { Information exchange } \\
\text { in the whole SC }\end{array}$ \\
\hline & 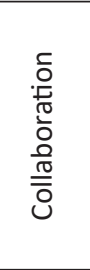 & $\begin{array}{l}\text { Weak or no } \\
\text { collaboration }\end{array}$ & $\begin{array}{l}\text { Intra-firm flexibil- } \\
\text { ity and collabora- } \\
\text { tion of functions } \\
\text { Limited cooper- } \\
\text { ation }\end{array}$ & $\begin{array}{c}\text { Functions are coupled in- } \\
\text { tra-firm } \\
\text { Functions are loosely connect- } \\
\text { ed to SC members } \\
\text { Inter-firm collaboration with } \\
\text { SC members in case of flexibil- } \\
\text { ity needs }\end{array}$ & $\begin{array}{l}\text { Inter-firm collaboration } \\
\text { to prepare flexibility } \\
\text { Connection between } \\
\text { internal and external } \\
\text { functions of key SC } \\
\text { partners }\end{array}$ & $\begin{array}{l}\text { Regular inter-firm } \\
\text { collaboration among } \\
\text { all SC members } \\
\text { Connection of internal } \\
\text { and external functions } \\
\text { with all SC members }\end{array}$ \\
\hline $\begin{array}{l}\frac{n}{c} \\
\frac{0}{n} \\
\frac{c}{0} \\
\frac{E}{0}\end{array}$ & 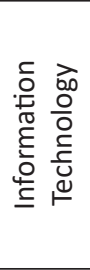 & $\begin{array}{c}\text { Information } \\
\text { Technology (IT) } \\
\text { has no relation to } \\
\text { flexibility }\end{array}$ & $\begin{array}{c}\text { Intra-firm IT } \\
\text { systems enabling } \\
\text { in-house flexibility } \\
\text { Majority use of } \\
\text { spreadsheets }\end{array}$ & $\begin{array}{c}\text { Inter-firm IT systems enabling } \\
\text { information exchange between } \\
\text { customers and suppliers } \\
\text { IT systems more consolidated } \\
\text { Increased use of integrat- } \\
\text { ed software among key SC } \\
\text { members }\end{array}$ & $\begin{array}{l}\text { Integration of flexibility } \\
\text { planning into systems } \\
\text { of key SC members }\end{array}$ & $\begin{array}{l}\text { Consolidated IT sys- } \\
\text { tems } \\
\text { IT systems completely } \\
\text { integrated along the SC }\end{array}$ \\
\hline & 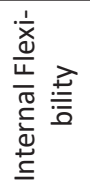 & $\begin{array}{l}\text { No internal flexi- } \\
\text { bility type }\end{array}$ & $\begin{array}{l}\text { E.g. labor, mate- } \\
\text { rial handling, and } \\
\text { machine }\end{array}$ & E.g. sourcing, and logistics & $\begin{array}{l}\text { E.g. expansion, and } \\
\text { information systems }\end{array}$ & $\begin{array}{l}\text { It is possible to im- } \\
\text { plement all internal } \\
\text { flexibility }\end{array}$ \\
\hline & 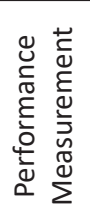 & $\begin{array}{l}\text { No flexibility } \\
\text { measures }\end{array}$ & $\begin{array}{l}\text { Measures for in- } \\
\text { tra-firm flexibility }\end{array}$ & $\begin{array}{l}\text { Measures that control and im- } \\
\text { prove reactively the inter-firm } \\
\text { flexibility }\end{array}$ & $\begin{array}{l}\text { Measures that improve } \\
\text { the flexibility of internal } \\
\text { and external functions } \\
\text { and processes with key } \\
\text { SC partners proactively }\end{array}$ & $\begin{array}{l}\text { Measures that plan, } \\
\text { control, and improve } \\
\text { all processes and } \\
\text { functions of the entire } \\
\text { SC proactively }\end{array}$ \\
\hline
\end{tabular}


Flexibility), where an end-to-end flexibility planning exists. At Level 2 (Intra-firm Flexibility), the flexibility is limited within the borders of the firm. At Level 3 (Reactive Flexibility), there is inter-firm flexibility. Finally, Level 4 (Proactive Flexibility) includes a structured preparation and utilization of flexibility potentials, with the key SC members managing flexibility proactively. Specifically, the maturity model includes five dimensions: Information Sharing, Collaboration, Information Technology, Internal Flexibility, and Performance Measurement. Figure 1 exhibits the maturity model.

The first dimension, information sharing, describes companies to spot variations in their business operations and to transform their processes accordingly (Gosain et al., 2004). As the two key elements of information sharing, the authors identified breadth and quality. High-quality information can be characterized as significant, accurate, complete, and enriching. The broad scope of knowledge allows all members of the SC to react upon sudden changes more appropriately. When information sharing takes place, those reactions to sudden changes can be orchestrated in advance, as the required amount of transparency and endurance apply (Stevenson and Spring, 2009). The more information is exchanged within an SC, and more communication can be observed between its members, the higher the level of flexibility that can be achieved (Gosain et al., 2004).

The second dimension, collaboration, can be regarded as a driving force for successful SCM. The level of collaboration refers to whether and how close the members of an SC work collaboratively (Horvath, 2001; Meng et al., 2011). Meng et al. (2011) described three sub-criteria of collaboration: working relationship, culture, and mutual help. Without any collaboration, companies are not able to optimize their processes alongside the real-time demand of their customers' clients. Neither are they able to fully understand and consider the limitations of their suppliers' suppliers (Horvath, 2001).

The next dimension, information technology, allows companies to gather, store, access, and analyze data. According to Swafford et al. (2008), integrating information technology can positively affect SCF, and companies can have a higher business performance within more agile SCs.

Many authors consider every internal flexibility as a single dimension (Sethi and Sethi, 1990; Koste and Malhotra, 1999; Parker and Wirth, 1999; Swafford et al., 2000; Duclos et al., 2003; Lummus et al., 2003; Sánchez and Pérez, 2005; Stevenson and Spring 2007; Jayant and Ghagra, 2013; Singh and Acharya, 2013). The maturity model from Fischer et al. (2016) grouped some flexibility, such as sourcing, labor, logistics, machine, and material handling in the same dimension: internal flexibility.
Finally, SCF performance is also influenced by performance measurement. This last dimension addresses the measurement of SCF performance inside the companies, i.e. to what extent and with what exact measures it is taken into account. Manufacturing and logistics executives are required to map the impact of each flexibility dimension, as not all dimensions are equally relevant for the overall company performance measures, and the most suitable dimensions shall be communicated for the sake of the company's competitive advantage (Sánchez and Pérez, 2005).

\section{RESEARCH METHOD}

The authors conducted a multiple case study, aiming to collect data to apply the SCF maturity model, reveal empirical insights of its use in the industry, and establish the relations among the flexibility dimensions of this model. The case study research method is appropriate to examine contemporary phenomena in a real-life setting when the boundaries between them are not clearly defined (Yin, 2009). Additionally, the method allows data to be collected from different sources, such as interviews, and observations (Voss et al., 2002).

The researchers selected three companies operating in three different sectors. Companies that are not concerned with SCF were not appropriate for the study because, at first glance, there is no relevant data to collect. The studied companies experienced variability in their demand, and manufacture high production volumes with a high product variety.

The research team followed a research protocol in all three case studies. A research protocol increases the research reliability, ensuring the rigor to validate the scientific research and guiding the data collection. Besides that, a protocol provides essential information on how to carry out case studies, aiming to standardize the research team procedures concerning collecting appropriate data in the studied companies (Yin, 2009).

The three sources of evidence were semi-structured interviews, researchers' observations, and internal documents. The use of three sources reduces the biases through triangulation, according to Yin (2009). The studied companies' names were changed to the letters $A$, $B$, and $C$ to maintain their anonymity. In each company, three employees were interviewed (Table 1). They were in charge of the same responsibilities, although the position names differ. 
Table 1. Interviewed Employees

\begin{tabular}{|c|l|}
\hline Case Companies & \multicolumn{1}{c|}{ People Interviewed } \\
\hline Company A & $\begin{array}{l}\text { - Supply planning manager } \\
\text { - Systems coordinator } \\
\text { - Supply planning analyst }\end{array}$ \\
\hline Company B & $\begin{array}{l}\text { - SC manager } \\
\text { - Procurement manager } \\
\text { - Information technology coordinator (in charge } \\
\text { of the performance measurement system) }\end{array}$ \\
\hline Company C & $\begin{array}{l}\text { - Purchase and supplier manager } \\
\text { - Quality manager } \\
\text { - Supplier development analyst }\end{array}$ \\
\hline
\end{tabular}

The semi-structured interviews with open questions were conducted using two research instruments, the interview script, and the interview control sheet (see Appendix). An interview script is a list containing relevant topics, which should be addressed during the interview. Each topic is a general issue and usually allows the respondent to address it widely, covering different aspects. The interview control sheet details each topic of the interview script and aims to provide a checklist for controlling the conversation and checking if all desired points were covered.

Regarding the data analysis, the researchers first analyzed the data gathered in each case study, named within-case analysis. The convergence between the interviews, documents, and observations can reveal patterns that detail how each company is classified in the SCF maturity model.

Afterward, the researchers examined the case studies data jointly, called cross-case analysis. Essentially, the analysis can produce a comparison between the multiple cases. This comparison aims to come up with similarities and differences between the multiple case studies. The researchers took notes of the collected data and transcribed the relevant statements made by the interviewees. The research team used these statements as empirical evidence, which are introduced in the next section.

\section{MULTIPLE CASE STUDIES}

This section describes the three case studies. The studied companies are classified in the corresponding level of each dimension of the identified SCF maturity model. It should be noted that each dimension could be classified into different levels for the same company.

\section{Company A}

Company $\mathrm{A}$ is an international consumer goods business that only sells directly to wholesalers or through e-com- merce using a logistics operator for delivering its products. This company produces different classes of products, e.g. home care and food, which are sold in more than 100 countries. According to the overall findings, Company A is classified within the first three SCF maturity levels, depending on the dimension, as described next.

Concerning the Information Sharing dimension, this company belongs to Level 2, as mainly internal data is shared among the areas. Although some logistics service providers can check which products are ready to be allocated to trucks, the integration of external SC data with internal data is minimal. The demand variation of Company $A$ is associated with food consumption.

"Every month we send our sales planning and the sales forecast for the next year to our suppliers. When we sell more than expected, we need to remake the production and material planning". (Supply planning manager)

However, there are particular actions that rate Company A at Level 3. For instance, in specific cases, significant suppliers check Company A's stock. Furthermore, Company A can access the stock and production of some important suppliers and inform them of future demand.

Collaboration occurs mainly intra-firm. The SC members do not work collaboratively; for example, the suppliers do not automatically react to the demand variations. Company A faces a collaboration challenge in the production sector. The workers of the factory earn their income based on the output reliability (OR) indicator. The OR measures the variation among the planned and the produced quantity.

"The factory employees have resistance to change the previously planned production because they receive their salary based on $O R$. Changing the demand during the week may affect the OR and hence the employees' salaries". (Supply planning manager)

However, even though the employees do not agree, Company A changes its production when it is necessary. Thus, Company A is classified at Level 2.

In the Information Technology dimension, Company A is at Level 3. Important information is shared via e-mails between Company $A$ and its suppliers or customers. Every day the Company receives new orders which get entered into its SAP system; the original order entry is compared daily with the expected order. The supply planning analyst pointed out that Company A utilizes an SAP system for receiving orders from customers. A few years ago, the Company implemented a planning and recommendation system suggesting the 
order amount that should be placed. This system has high importance inside Company A; some of its advantages are agility in the order process, assertiveness, and less human error.

Regarding the Internal Flexibility dimension, Company A can be classified mainly at Level 2 . The machine operation flexibility depends on the period of the year. Usually, the machines work with $85 \%$ of their capacity; therefore, it is simple to react to demand variations. On the other hand, in a specific period of the year in which the workload of the production line is at $100 \%$, it is not possible to respond to the increasing demand.

The low labor flexibility is a bottleneck at this company.

"The production lines have different technologies, and then one worker can operate only one kind of machine. If we want to contract new employees, it is necessary to wait three months". (Supply planning manager)

Besides that, there are other reasons which hinder labor flexibility, such as the limited capacity of labor: the company has exclusive operators per production line, if one operator is absent from work; thus, all operations in the respective production line will stop.

Concerning logistics flexibility, Company $A$ is responsible for the logistics of some of its suppliers. The company contracts trucks and drivers; in that way, the accuracy of receiving the raw materials is improved. Company $A$ has limited sourcing flexibility; it has only one supplier for many products due to the restricted rules to contract a new supplier. Hence, it faces a lack of material, which impacts the whole chain. However, suppliers who sell products with high margin and volume, i.e. critical materials, have different handling; therefore, there is a plan for their delivery.

Finally, related to the Performance Measurement dimension, Company $A$ is classified as Level 1 because it does not have flexibility measures. Although there is no flexibility measure, Company $A$ uses different measures for its SC members. For its suppliers, Company A measures the on time in full, which indicates whether the goods were delivered on-time and with the correct required amount. Furthermore, the company measures to which degree it delivers at the planned time and the correct amount, and which amount was not delivered due to a lack of stock. Every month, all managers receive the indicators by e-mail and also have meetings for checking the performance measures.

\section{Company B}

Company $B$ is a multinational manufacturer of stationery that produces several million goods per day. Those highly diverse goods are sold to the wholesalers directly. The following section presents the empirical findings for each SCF maturity level dimension. Company B can be placed within the first three SCF maturity levels of all dimensions, as detailed next.

Related to the Information Sharing dimension, the Supply Chain department shares its forecast with the Sales and Marketing department. At Company B, some external and internal SC data is integrated. For example, the delivery date of the national supplier is sent to the internal areas of Planning and Logistics, whereas the logistic service provider and the Purchase department receive the information concerning the delivery date of the international suppliers by e-mail.

Even though Company B does not share plans with parties outside the firm, it still checks its suppliers' capacity on special occasions. As the SC manager pointed out, they inform the Procurement department about increased consumption of specific raw materials whenever the demand for new products is available. The Procurement department will then inquire about the utilized capacity of the supplier. Additionally, the major or strategically relevant suppliers will get informed about Company B's annual sales forecast, which sometimes also gets used to navigating price negotiations. According to the statement of the SC manager, Company $B$ has several thousands of direct customers and holds concrete data of only one hundred of them. Most of the customers hardly use computers, thus making data gathering and monitoring almost impossible. Due to these characteristics, Company B is ranked at maturity Level 3.

Concerning the Collaboration dimension, Company B is classified at Level 2 as the flexibility is only created intra-firm, and the cooperation is limited. The collaboration procedure was changed once, in a rare event, when the sales of a specific product suddenly boosted. By deactivating a disused plant, it was possible to increase the production capacity on short notice. The production and demand for raw materials were suddenly increased; thus, the suppliers quickly reached their safety stock. Therefore, managers checked the demand figures of the original product, produced at an external member of the SC. Considering this event, Company $B$ could be at maturity Level 4. By improving its level of collaboration, Company B could observe closer the demand of its customers' customers, and optimize its operations.

Taking into account the Information Technology dimension, there are few retailers that can access the company's internal system and add their forecast. However, they prefer to include this information in Excel spreadsheets and 
Brazilian Journal of Operations \& Production Management Volume 16, Número 3, 2019, pp. 436-447

DOI: 10.14488/BJOPM.2019.v16.n3.a7 send it by e-mail. Sometimes, the SAP system exchanges order information with a supplier automatically. However, to avoid ordering wrong quantities, the purchase manager prefers not to activate automatic order points in SAP, as this would otherwise require the data to be totally correct. When the logistics operators feature highly reliable information systems, it is possible to use their online portal for data exchange. Moreover, Company B monitors the stock and sales of big customers through e-mail and worksheet, in order to avoid the bullwhip effect. The suppliers of Company $B$ cannot access the company database because its material management is made inside the SAP system. As the Information Technology systems of Company $B$ enable a form of inter-firm information exchange, it is classified as maturity Level 3.

Considering the Internal Flexibility dimension, the machine's operation and work shifts are adapted reactively. For example, the machines are adjusted to work with $85 \%$ of the capacity. If the demand is high, the machines can use more of their capacity. The work shift also changes according to demand. As the logistics service is outsourced, it needs to be planned because the trucks also operate for other companies. A purchase matrix was elaborated in order to find more than one supplier for the main products or items that need more flexibility. Using this matrix, Company $B$ has more sourcing flexibility, and it works proactively with critical suppliers, anticipating risks and establishing strategies. The negotiation power increases and the risks are reduced when companies have more than just one supplier for the same material. Besides that, Company B keeps a stock of some suppliers in its plant. Company B has mainly machine and sourcing flexibility. Consequently, concerning the Internal Flexibility dimension, it can be classified as maturity Level 3.

The managers utilize performance measures for making decisions. The leading indicators are on time in full, profit margin, stock accuracy, and management shipping. The information technology coordinator explained that the measures are calculated monthly by using the information contained in the SAP, and that it is difficult to represent flexibility. In that way, none of the Company B's performance indicators measure flexibility. For this reason, this company is classified at Level 1 in the Performance Measurement dimension.

\section{Company C}

Company $\mathrm{C}$ is an international company that sells white line goods. It is located in four countries and produces 5.5 million units of its main product per year. Company $\mathrm{C}$ is classified within the first four levels of the SCF maturity model as depicted below.
Regarding the Information Sharing dimension, Company $C$ informs its suppliers when demand variation occurs. Every day, Company $\mathrm{C}$ reports how many products were sent to its customers.

\begin{abstract}
"When our demand increases, we request our suppliers to check how their capacity is. On the other hand, when our demand decreases, we verify if this information is correct and what we should do with our stock". (Supplier development analyst)
\end{abstract}

The Quality department informs the suppliers whenever it finds noncompliant products.

\begin{abstract}
"The first flow of communication to our supplier is when we find a noncompliant item. After that, we need agility from our supplier in order to answer our customer. Then, aiming to attend our internal and external customers, we call or send emails to our suppliers explaining the problem, e.g. we send photos. When we develop a new item, we ask our suppliers to send us the needed documentation". (Quality manager)
\end{abstract}

Besides that, the Quality department has periodic meetings with a specific customer, in order to verify the effectiveness of corrective actions. Company $\mathrm{C}$ usually makes its orders using an online system. As Company $C$ integrates some internal data with external SC data, it is classified as maturity Level 3.

Company $\mathrm{C}$ has inter-firm regular Collaboration with critical suppliers to prepare flexibility.

"We classify our suppliers regarding their prod-
uct price; criticality; and quantity of product that
we buy. Our main suppliers, which sell products
costing more than 1 million, have a subsidiary in
our company. Also, critical suppliers who need a
long time to deliver their products are allocated
inside our company. All of these suppliers are re-
sponsible for their inventory and shipping costs.
Therefore, we have the flexibility to supply our
production line". (Purchase and supplier manag-
er)

Moreover, some of these suppliers also have part of their inventory allocated to Company C. Besides that, a big customer wants the stock from Company $\mathrm{C}$ stored near its plant. In that way, Company $\mathrm{C}$ is responsible for keeping its stock according to this customer's needs. When Company C changes its order amounts (e.g., decreases the order volume), the suppliers are informed quickly in order to adapt according to the variation. There is an intra-firm collabora- 
tion for avoiding waste when an order is canceled and the production line is already producing. Company $\mathrm{C}$ checks if this material can still be sold. According to the characteristics mentioned above, Company $\mathrm{C}$ is classified at Level 4 in the Collaboration dimension.

Concerning the Information Technology dimension, internal information such as production reports is exchanged mainly using spreadsheets. However, some information from Company $\mathrm{C}$ is exchanged inter-firm, using an online system.

"We have an online portal which informs our suppliers when our stock is low. Besides, our orders go directly from the Oracle system to this online system, where the suppliers can check our needs". (Purchase and supplier manager)'

The supplier development analyst clarified how the online portal works; the Oracle system sends the demand information to the online portal. In this portal, important suppliers can verify the quantity and delivery date, at which their material is needed. In the case of small suppliers, the order is sent directly to them. The quality manager criticized how the Oracle system works.

"Our company uses the global system Oracle ERP with very few customizations options. It occurs because the responsible employees do not want to make any effort to include a new Oracle version. The benefit of this global system is that the whole company can access the data; on the other hand, we cannot change it or enter additional information". (Quality manager)

Although the Oracle system has some limitations, the use of an online portal for exchanging inter-firm information among Company $\mathrm{C}$ and its suppliers classifies this Company as Level 3 of the Information Technology dimension.

In the Internal Flexibility dimension, Company $\mathrm{C}$ can be classified at Level 3. This company changes the machine operation and production sequence according to its demand variation. Company $\mathrm{C}$ can react quickly since it works with an idle machine operation capacity of approximately $50 \%$. This Company has labor flexibility, adjusting the shift and the number of workers according to demand. The logistic service can quickly react when flexibility is necessary.

"Our logistic process is milk run; we contract trucks which take our supplies according to optimal operation. These trucks have the exact time for taking each supply. This logistic process guarantees the daily delivery of material, the correct material quantity and minimizes inventory and logistics service". (Purchase and supplier manager)
Company $\mathrm{C}$ is concerned about sourcing flexibility. It aims to have more than one supplier for the same product.

"Our goal is to eliminate our material and technological dependency from our suppliers. We do not want to have an exclusive supplier; we try to have around three suppliers for the same product. When it is not possible, it is necessary to have a strict contract and enough stock". (Purchase and supplier manager)

Related to the Performance Measurement dimension, no flexibility measure was observed. Thus, Company $\mathrm{C}$ is classified as Level 1. However, this company has other performance measures. Company $\mathrm{C}$ measures the performance of its suppliers. The customers evaluate the performance of Company C; for example, they check the number of noncompliant parts, and the quantity of products which presented defect at the end-customer house. Besides that, a production report exhibits the planned and executed production daily. At the end of the month, a complete report with this information is presented to all managers.

\section{DISCUSSION}

After collecting all the information described above, the findings of the three case studies were compared focusing on the maturity of each five dimensions of the SCF maturity model. This comparison allows for identifying the similarity and distinction between each studied company. Figure 2 represents the classification of Companies A, B, and C in the SCF maturity model. According to the SCF maturity assessments, the companies do not have the same level of maturity in all dimensions. Corroborating the conclusion that flexibility is multi-dimensional, if a company is flexible in one dimension, it does not automatically mean that this company will have the same flexibility in other dimensions (Stevenson and Spring, 2007).

Although Company A integrates some of its data with key suppliers and logistics service providers, internal data is mainly shared between functional units. In contrast, Companies B and C partially integrate internal and external SC data, e.g. sharing sales forecast or demand variation with key suppliers, and accessing stock information of some customers. In line with Gosain et al. (2004), the findings confirm that sharing information between SC members can support the identification of changes in processes and reactions to these changes correctly and quickly. All companies should consider increasing their information sharing level. Stevenson and Spring (2009) stated that information sharing can improve transparency and create trust; however, no interviewee mentioned these characteristics.

Unlike the other studied companies, Company $\mathrm{C}$ has its collaboration dimension classified at Level 4 , because its 
Brazilian Journal of Operations \& Production Management

Volume 16, Número 3, 2019, pp. 436-447

DOI: 10.14488/BJOPM.2019.v16.n3.a7 main suppliers have their subsidiary and inventory allocated inside the company. This can improve SCF, as suppliers can react quickly to production line variations and the lack of stock is more easily avoided. Companies A and B should improve their inter-firm collaboration in order to optimize their operations. Company B experimented working collaboratively with proactive flexibility and thus may use it for further situations. The collaboration's sub-criterion "culture", presented by Meng et al. (2011), was observed in Company $A$ as there are employees who behave defensively, since the income is based on a measure (i.e. OR indicator) that is modified with the variations of demand. This may harm collaboration, and it is necessary to find a solution to this problem.

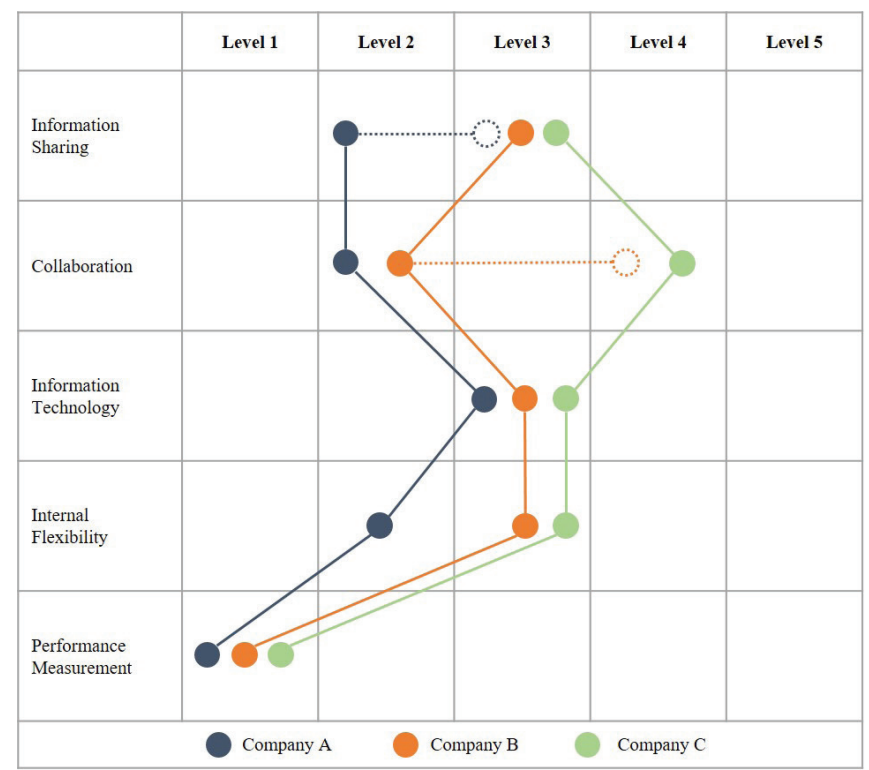

Figure 2. SCF maturity assessment of Companies A, B, and C Source: Own figure

An intra-firm information technology system, which enables in-house flexibility, is valuable. In Company C, many areas can access the production report. This is related to the findings by Swafford et al. (2008) that emphasized the importance to invest in information technology which enables enterprise-wide coordination and integration intra-firm. Besides that, inter-firm information technology system enables information exchange, and can support flexibility management, bringing benefits to the SCF. The companies utilize SAP system with different goals: Company A receives orders from its main customers, whereas Company $B$ exchanges order information with its major suppliers. Moreover, the major suppliers of Company B can access their orders using an online portal. Furthermore, Company A created a planning and recommendation system, which suggests the order quantity. The three companies under observation could increase the agility of their SCs by enhancing the integration of information technology.
The studied companies are aware that it is disadvantageous to maintain a unique supplier for their main products. However, only Companies B and C work preventively to avoid such situations. Company B has its purchase matrix, while Company $C$ always plans to have around three suppliers for the same product. In that way, these two companies establish contracts with their key suppliers and do not face problems in the production line due to lack of material. Companies that closely follow their key supplier can be more flexible, as they will be informed faster about unexpected events at their supplier. Hence, they can act quickly to avoid bottlenecks in their production line. Although Company $A$ has specific strategies for critical suppliers, its rigor brings many problems such as lack of raw material. These findings correspond to previous research (Thomé et al., 2014a) that found that SC manages the increased demand by using, for example, sourcing flexibility.

The machine flexibility in Company A depends on the period of the year. In Company $B$, it is adapted reactively and is combined with the work shift. On the other hand, in Company $C$ it changes according to its demand. Companies $A$ and $C$ are responsible for contracting logistics providers, who receive some of their supplies. Consequently, both companies can be more flexible, as they do not need to wait for the supplier to deliver. The goods can be delivered according to their necessities, and they can minimize their inventory.

In some cases, external elements, i.e. those which companies cannot control, affect the SCF. As an example, Company $A$ needs to handle labor legislation, causing difficulties with achieving labor flexibility. In contrast, Companies B and $C$ do not have these issues and can be more flexible with their labor.

Seebacher and Winkler (2015) stated that companies need an approach that allows an ongoing and feasible measuring of SCF to evolve their flexibility according to their goals. However, the findings show that the studied companies do not consider flexibility measures. This absence of flexibility measures renders difficulties when striving for external flexibility. Companies can quickly notice the area that needs flexibility and to which extent it is required when respective flexibility indicators exist. Consequently, the lack of such indicators affects control and planning activities. None of the companies under observation utilizes measures to simplify the uncovering of flexibility shortages.

The relations between the five SCF maturity model dimensions are established using the empirical findings from the multiple case study (see Figure 3). The Information Sharing dimension can be seen as the starting point for all other dimensions. Internal Flexibility (e.g. machine, labor, logistics, and sourcing) can be achieved and enabled by either the Collaboration or the Information Technology dimension. 
In the end, the Performance Measurement dimension evaluates the level of internal flexibility, when compared to the predefined and desired outputs (i.e. new products, product mix, volume, and delivery).

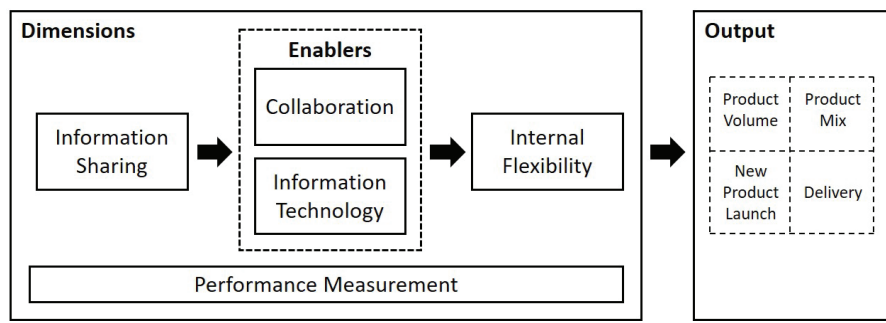

Figure 3. Relations of SCF maturity model dimensions Source: Own figure

\section{CONCLUSION}

This research sheds light on a better comprehension of SCF maturity using the single SCF maturity model found in the literature to conduct an external application in different companies. The SCF maturity model has five levels of maturity ranging from "no flexibility" to "paradigmatic flexibility". The five dimensions of this model are Information Sharing, Collaboration, Information Technology, Internal Flexibility, and Performance Measurement.

Analyzing the empirical findings, it is possible to conclude that there are some industry characteristics which influence SCF. As a piece of evidence, Company $A$ is very restricted to admit new suppliers and prefers to work with only an exclusive one, even knowing that its entire chain will be affected if such supplier is not able to deliver the right amount of product at the correct time.

This study establishes the relations between the flexibility dimensions of the SCF maturity model based on empirical evidence. Information Sharing is needed in order to allow flexibility, whereas Information Technology and Collaboration are the enablers to achieve Internal Flexibility, such as machine, labor, logistic, and sourcing flexibility. Lastly, Performance Measurement monitors the internal flexibility and checks whether the external flexibility was achieved.

The studied companies are classified into different maturity levels for each flexibility dimension. For example, in the Information Sharing dimension, Company $\mathrm{C}$ allows its main suppliers to access its forecasts and know the quantity and time that is necessary to produce and deliver the supplies. Therefore, this Company is more mature in that dimension than the other two that do not share their forecast.
The external application of the SCF maturity model was conducted through multiple case studies in companies from different business sectors. As the studied companies are classified mainly within the first three levels of the SCF maturity model, future research can be conducted aiming to check companies which are classified within the more advanced levels, i.e. Levels 4 and 5 . Besides that, as the studied companies are from diverse manufacturing fields, further studies should be conducted in companies from the same industrial sector in order to compare the SCF maturity of these companies. Although flexibility indicators are important, none of the studied companies use these measures, and therefore, future work could investigate why the companies are not mature in the Performance Measurement dimension and what can be done to make them start measuring SC flexibility.

\section{REFERENCES}

Ayers, J. B. and Malmberg, D. M. (2002), "Supply chain systems: are you ready?", Information Strategy: The Executive's Journal, Vol. 19, No.1, pp. 18-27.

Bowersox, D. J. et al. (2000), "Ten mega-trends that will revolutionize supply chain logistics", Journal of business logistics, Vol. 21, No. 2.

Duclos, L. K. et al. (2003), “A conceptual model of supply chain flexibility", Industrial Management \& Data Systems, Vol. 103, No. 6, pp.446-456.

Dwaikat, N.Y. et al. (2018), "How does information sharing affect first-tier suppliers' flexibility? Evidence from the automotive industry in Sweden", Production Planning \& Control, Vol. 29, No. 4, pp. 289-300.

Esmaeilikia, M. et al. (2016), "A tactical supply chain planning model with multiple flexibility options: an empirical evaluation", Annals of Operations Research, Vol. 244, No. 2, pp. 429-454.

Fischer, J.-H. et al. (2016), "Development and Application of a Maturity Measurement Framework for Supply Chain Flexibility", Procedia CIRP, Vol. 41, pp. 514-519.

Garcia Reyes, H. and Giachetti, R. (2010), “Using experts to develop a supply chain maturity model in Mexico", Supply Chain Management: An International Journal, Vol. 15, No. 6, pp. 415-424.

Gerwin, D. (1993), "Manufacturing flexibility: a strategic perspective", Management Science, Vol. 39, No. 4, pp. 395-41.

Gosain, S. et al. (2004), "Coordinating for Flexibility in e-Business Supply Chains", Journal of Management Information Systems, Vol. 21, No. 3, pp. 7-45.

Hellingrath, B. and Pfeiffer, D. (2011), "Analyzing the Volume Flexibility of Transportation Planning in Supply 
Brazilian Journal of Operations \& Production Management Volume 16, Número 3, 2019, pp. 436-447

DOI: 10.14488/BJOPM.2019.v16.n3.a7
Chains", Herausforderungen, Chancen und Lösungen Band II.

Horvath, L. (2001), “Collaboration: the key to value creation in supply chain management", Supply Chain Management: An International Journal, Vol. 6, No. 5, pp. 205-207.

Huo, B. et al. (2018), "Supply chain flexibility concepts, dimensions and outcomes: an organizational capability perspective", International Journal of Production Research, Vol. 56, No. 17, pp. 5883-5903.

Jayant, A. and Ghagra, H. S. (2013), "Supply Chain Flexibility Configurations: Perspectives, Empirical Studies and Research Directions", International Journal of Supply Chain Management, Vol. 2, No. 1, pp. 21-29.

Koste, L. L. and Malhotra, M. K. (1999), “A theoretical framework for analyzing the dimensions of manufacturing flexibility", Journal of Operations Management, Vol. 18, No. 1, pp. 75-93.

Lockamy III, A. and McCormack, K. (2004), "The development of a supply chain management process maturity model using the concepts of business process orientation", Supply Chain Management: An International Journal, Vol. 9, No. 4, pp. 272-278.

Lummus, R. R. et al. (2003), "Supply Chain Flexibility: Building a New Model", Flexible Systems Management, Vol. 4, No. 4, pp. 1-13.

Manders, J. H. M. et al. (2016), "Exploring supply chain flexibility in a FMCG food supply chain", Journal of Purchasing and Supply Management, Vol. 22, No. 3, pp. 181-195.

Manders, J. H. M. et al. (2017), "Supply chain flexibility: A systematic literature review and identification of directions for future research", The International Journal of Logistics Management, Vol. 28, No. 4, pp. 964-1026.

Meng, X. et al. (2011), "Maturity Model for Supply Chain Relationships in Construction", Journal of Management in Engineering, Vol. 27, No. 2, pp. 97-105.

Parker, R. P. and Wirth, A. (1999), "Manufacturing flexibility: Measures and relationships", European Journal of Operational Research, Vol. 118, No. 3, pp. 429-449.

Paulk, M. C. et al. (1993), “Capability maturity model, version 1.1", IEEE Software, Vol. 10, No. 4, pp. 18-27.

Sánchez, A. M. and Pérez, M.P. (2005), "Supply chain flexibility and firm performance: a conceptual model and empirical study in the automotive industry", International Journal of Operations \& Production Management, Vol. 25, No. 7, pp. 681-700.

Seebacher, G. and Winkler, H. (2015), “A capability approach to evaluate supply chain flexibility", International Journal of Production Economics, Vol. 167, pp. 177-186.
Sethi, A. K. and Sethi, S. P. (1990), "Flexibility in manufacturing: a survey", International Journal of Flexible Manufacturing Systems, Vol. 2, No. 4, pp. 289-328.

Singh, R. K. and Acharya, P. (2013), "Supply Chain Flexibility: A Framework of Research Dimensions", Global Journal of Flexible Systems Management, Vol. 14, No. 3, pp. 157-166.

Slack, N. (1987), "The flexibility of manufacturing systems", International Journal of Operations \& Production Management, Vol. 7, No. 4, pp. 35-45.

Stevenson, M. and Spring, M. (2007), "Flexibility from a supply chain perspective: definition and review", International Journal of Operations \& Production Management, Vol. 27, No. 7, pp. 685-713.

Stevenson, M. and Spring, M. (2009), "Supply chain flexibility: an inter-firm empirical study", International Journal of Operations \& Production Management, Vol. 29, No. 9, pp. 946-971.

Sushil (2012), "Flexibility Maturity Model: Possibilities and Directions", Global Journal of Flexible Systems Management, Vol. 13, No. 2, pp. 75-76.

Swafford, P. M. et al. (2000), "A model of global supply chain agility and its impact on competitive performance", Proceedings of the 31st National DSI Meeting, Vol. 520, No. 404, pp. 1037-1039.

Swafford, P. M. et al. (2008), "Achieving supply chain agility through IT integration and flexibility", International Journal of Production Economics, Vol. 116, No. 2, pp. 288-297.

Thomé, A. M. T. et al. (2014a), "A multi-tier study on supply chain flexibility in the automotive industry", International Journal of Production Economics, Vol. 158, pp. 91-105.

Thomé, A. M. T. et al. (2014b), "Extending the flexibility debate beyond the organization's boundaries to the supply chain: a case study", 21st European Operations Management Association Conference. Palermo.

Upton, D. M. (1994), "The management of manufacturing flexibility", California Management Review, Vol. 36 No. 2, pp. 72-89.

Upton, D. M. (1995), "What really makes factories flexible?", Harvard Business Review, Vol. 73, No. 4, pp. 74-84.

Vickery, S. N. et al. (1999), "Supply chain flexibility: an empirical study", Journal of Supply Chain Management, Vol. 35, No. 2, pp. 16-24.

Voss, C. et al. (2002), "Case research in operations management", International Journal of Operations \& Production Management, Vol. 22, No. 2, pp. 195-219. 
Wadhwa, S. and Rao, K. S. (2002), "Framework for a flexibility maturity model", Global Journal of Flexible Systems Management, Vol. 3, No. 2/3, pp. 45-55.

Yin, R. K. (2009), Case study research: design and methods, 4th ed., SAGE Publications, Thousand Oaks.

Yu, K. et al. (2015), “Operational flexibility: Review and meta-analysis", International Journal of Production Economics, Vol. 169, pp. 190-202.

Zhang, Q. et al. (2003), "Manufacturing flexibility: defining and analyzing relationships among competence, capability, and customer satisfaction", Journal of Operations Management, Vol. 21, No. 2, pp. 173-191.

\section{APPENDIX}

\section{Interview script}

Note: Before the interview, it was asked data on the interviewee (position, main responsibilities, amount of time working in the company), and data about the company (strategy, market, customers), its supply chain, and main products and processes. Main topics mentioned during the interview are presented below.

1. How does the company cope with the supply chain (external and internal) variation?

2. Collaboration with suppliers to cope with a variation.

3. Information sharing across the company supply chain.

4. Information technology platform to support information sharing.
5. Measures of supply chain performance and flexibility.

6. Use of performance measure to make decisions in supply chain management.

7. Performance measurement information sharing.

8. Information technology platform to support the performance measurement system.

\section{Interview control sheet}

Note: The points introduced below were used as a way to control whether the points of the central questions of the interview script were mentioned during the interview.

1. Sourcing, labor, logistics, machine, material handling, new product, and information systems.

2. Reactive and proactive.

3. Internal and external.

4. Internal and external software and systems.

5. How are the indicators measured? Only internal indicators or for the whole supply chain?

6. How to make decisions, flexibility measures.

7. Communication, infrastructure for communication, reports, and information dissemination.

8. IT platform.

Received: 30 Apr 2019

Approved: 20 May 2019

DOI: 10.14488/BJOPM.2019.v16.n3.a7

How to cite: Mello, R.; Hellingrath, B.; Martins, R. A. (2019), "Lessons from empirical studies in supply chain flexibility: a maturity perspective", Brazilian Journal of Operations \& Production Management, Vol. 16, No. 3, pp. 436-447, available from: https://bjopm.emnuvens.com.br/bjopm/article/view/850 (access year month day). 